\title{
Pharmacological profile and effects of mitotane in adrenocortical carcinoma
}

\author{
Claudia Corso ${ }^{1}$, Alexandra Acco ${ }^{2}$, Camila Bach ${ }^{1}$, Sandro Bonatto ${ }^{1}$, Bonald Figueiredo ${ }^{1}$, \\ and Lauro Souza ${ }^{1}$ \\ ${ }^{1}$ Instituto de Pesquisa Pelé Pequeno Príncipe \\ ${ }^{2}$ Federal University of Parana
}

May 28, 2020

\begin{abstract}
Mitotane is the only drug approved for treating adrenocortical carcinoma (ACC) by the FDA since 1959, despite the controversy regarding its efficacy in prolonging patient survival. This drug has cytotoxic effects on tumor tissue by inducing cell death and antisecretory effects on adrenal cells by inhibiting the synthesis of adrenocortical steroids involved in the pathogenesis of ACC. To reach the therapeutic plasma concentration, high doses of mitotane are usually necessary, which may result in several adverse effects. This suggests that important pharmacological features are involved in the mechanisms of action of this drug, such as first pass metabolism, tissue accumulation, and extensive time needed for drug elimination. However, few studies have reported the pharmacological aspects of mitotane, and they did not provide sufficient evidence regarding monitoring mitotane's therapeutic effects. Therefore, this review summarized the chemistry, pharmacokinetics and pharmacodynamics, therapeutic effects, toxic effects, and new perspectives of mitotane treatment that are currently under investigation. Understanding the pharmacological profile of mitotane can improve the monitoring and efficacy of this drug in ACC treatment and can further provide useful information for the development of new drugs with specific action against ACC with fewer adverse effects.
\end{abstract}

\section{Contents}

1. Introduction 5

2. Chemistry 7

3. Pharmacological aspects 8

4. Pharmacokinetics 8

5. Absorption 8

6. Distribution 9

7. Metabolism 11

8. Elimination 14

9. Pharmacodynamics and pharmacological effects 15

10. Toxicity 20

11. New perspectives for mitotane treatment 22

12. Conclusions and future directions 25

\section{Introduction}

Adrenocortical carcinoma $(\mathrm{ACC})$ is a rare endocrine malignancy arising from one of the three cortical layers of the adrenal gland. ACCs can cause an increase in the production of one or more steroid hormones, such as cortisol, androgens, and aldosterone, resulting in clinical manifestations of Cushing's syndrome, virilization (facial acne, pubic pilification, hirsutism, increase in muscle mass), and high blood pressure, respectively. Clinical manifestations are variable, and the prognosis of ACC is often unfavorable, especially at older ages 
[1,2]. The general incidence of ACC is 1.7-2.0 cases/million/year among adults, whereas it is even rarer among children in most countries (0.2-0.3 cases/million/year); it is more common among women [2]. One exception is Southern Brazil, wherein the ACC incidence is higher in children than in adults [3], reaching a rate of 3.4-4.2 per million children versus an estimated worldwide incidence of 0.3 per one million children younger than 15 years [4].

Currently, mitotane is the only approved drug, as single or adjuvant treatment, for post-operative or inoperable ACC. The daily dose usually ranges between 2 and up to $10 \mathrm{~g}$ to reach the ideal plasma concentration with tolerable toxicity, which is $14-20 \mathrm{mg} \mathrm{L}^{-1}[5,6]$. The mean dose is $4 \mathrm{~g}_{\text {day }}{ }^{-1}$ for adults and $4 \mathrm{~g} \mathrm{~m}^{2} /$ day $^{-1}$ for children for ACC stage $3 / 4$ and recurrence of stage $1 / 2[7,8]$. In most patients, the steady state is reached after 3 months of daily treatment [6,9]. Nevertheless, patients experienced several adverse events of the gastrointestinal (diarrhea, nausea, vomiting, and anorexia) and central nervous (confusion, ataxia, and dizziness) systems [10] and many other adverse effects that were not well documented (ClinicalTrials.gov Identifier: NCT00568139), limiting its therapeutic use mainly among pediatric ACC patients.

Mitotane [1-(o-chlonophenyl)-1-(p-chIorophenyl) 2,2-dichioroethane], also known as o,p'-DDD, was isolated in 1940 from the insecticide dichlorodiphenyltrichloroethane (DDT). The adrenolytic effect of mitotane was first reported in dogs for inducing selective necrosis in the zona fasciculata and zona reticularis of the adrenal cortex $[11,12]$. The first clinical evidence was published in 1959, when the efficacy of mitotane for the treatment of ACC was reported in male patients [13]. Thereafter, even though the mechanism of action was unclear, mitotane was rapidly approved by the Food and Drug Administration (FDA) for ACC treatment, and it became commercially available in a tablet form as the reference product Lysodren ${ }^{(\mathrm{r})}$ [14].

The first line treatment for ACC after surgery is mitotane monotherapy for less progressive ACC or mitotane plus chemotherapy, such as etoposide, doxorubicin, and cisplatin (mitotane + EDC), to treat more aggressive forms $[15,16]$. However, when first line therapy fails, mitotane can also be employed in combination with streptozotocin, vincristine, gemcitabine + capecitabine, and avelumab [15]. A recent meta-analysis revealed that mitotane monotherapy with or without radiotherapy, decreased the recurrence rate and mortality after tumor resection among patients without distant metastasis [17]. However, the efficacy of mitotane combined with chemotherapy is still unclear. To evaluate if adjuvant mitotane + EDC, after resection of ACC, has survival benefits for patients, we searched for "mitotane AND survival AND adrenocortical carcinoma OR adrenal tumor" in PubMed, Cochrane, Web of Science, and Scopus between November and December of 2019. We identified 851 records in the databases. Of these, 298 were duplicated and 553 were screened by title and abstract evaluation. Thirty-one full-text articles were assessed for eligibility. None of these articles met the inclusion criteria for meta-analysis of the benefits of adjuvant mitotane plus chemotherapy in prolonging the survival of patients. Thus, the clinical efficacy of mitotane in prolonging patient survival is still controversial due to a lack of randomized controlled studies. However, some clinical trials of mitotane + EDC for advanced ACC, recently registered in the Cochrane library, may provide useful data for the evaluation of patient survival in the future. Among the seven trials evaluating mitotane therapy plus chemotherapy identified in our study, only two have monitored the plasma mitotane levels [18,19] (Table 1).

Even after five decades of the mitotane approval by FDA, few studies have addressed pharmacological aspects of mitotane, probably because ACC is a rare disease. Therefore, better understanding of the effects of mitotane on ACC is needed to improve the clinical monitoring of its efficacy and development of new drugs with specific action against ACC with fewer toxic effects. Thus, this review summarized the chemistry, pharmacokinetic and pharmacodynamic features, and therapeutic and toxic effects of mitotane and the new formulations containing this drug.

\section{Chemistry}

Unlike DDT, the mitotane molecule exists in two configurations depending on the position of the chlorine element in the benzene ring: the position ortho in one ring and the position para in another ring. These mitotane configurations are characterized by the presence of an asymmetric chiral carbon atom that gives rise to two enantiomeric ( $R$ and $S$ ) molecules. Considering that mitotane is available as a racemic mixture, 
both enantiomers, (S)-(-)-o,p'-DDD and (R)-(+)-o,p'-DDD (Fig. 1A) are present in the commercial drug. Furthermore, it has been demonstrated that mitotane metabolism involves two reactions via $\alpha$ - and $\beta$ hydroxylation. $\alpha$-hydroxylation forms the metabolite o,p'-DDE (DDE), whereas $\beta$-hydroxylation forms o,p'dichlorodiphenyl acyl chloride (DDAC). DDAC has a strong affinity for biological nucleophiles, which can acylate different cellular molecules; otherwise, DDAC could be rapidly converted to the metabolite o,p'-DDA (DDA) in the presence of water (Fig. 1B).

\section{Pharmacological aspects}

2. Pharmacokinetics

\subsubsection{Absorption}

Mitotane has poor water solubility $\left(0.1 \mathrm{mg} \mathrm{mL}^{-1}\right.$ at $\left.25^{\circ} \mathrm{C}\right)$, being better soluble in organic solvents such as ethanol (20 $\left.\mathrm{mg} \mathrm{mL}^{-1}\right)$, dimethylsulfoxide (DMSO) $\left(30 \mathrm{mg} \mathrm{mL}^{-1}\right)$, and dimethyl formamide (DMF) (PubChem; Cayman Chemical). In pre-clinical studies, mitotane was often dissolved in olive oil or DMSO followed by aqueous buffer, to reach ideal plasma concentrations [24,25]. In clinical tests, mitotane reached the maximum absorption when administered together with dietary lipids such as high fat milk, chocolate, or oil emulsions, which increased its absorption by 5 -fold compared to that of mitotane tablets [26].

Although mitotane (single dose of $2 \mathrm{~g}$ ) reached the maximal plasma concentration of $0.0016 \mathrm{mg} \mathrm{mL}-1$ (data from 9 patients) $10 \mathrm{~h}$ after administration [26], the time to reach the ideal plasma concentration (14 mg L-1) among ACC patients was around 116 days with an accumulative dose of approximately $626 \mathrm{~g}$ (data from 53 patients) [27]. However, it is difficult to determine mitotane bioavailability since there is no data about in vitro intestinal absorption, bioavailability of intravenously administered mitotane, or hepatic extraction to determine whether mitotane has first-pass metabolism. Despite the lack of information about the pharmacokinetics of mitotane, there is no doubt that the oral bioavailability is low, probably due to poor absorption and extensive metabolism. Indeed, patients required high doses $\left(2-10 \mathrm{~g} \mathrm{day}^{-1}\right)$ to reach the therapeutic plasma concentration (14-20 $\mathrm{mg} \mathrm{L}^{-1}$ ) and the steady state was reached only about 3 months after treatment initiation $[5,6]$. In addition, high variation in plasma concentration was observed with different doses among patients probably due to the basic individual variability in body mass index, sex, age, and metabolic enzyme activity. Metabolic cytochrome P450 (CYP) polymorphisms might play an important role in mitotane absorption. In fact, D'Avolio et al. (2013) [27] demonstrated that the polymorphism of CYP2B6 was positively correlated with higher plasma mitotane concentration. In patients with any stage ACC treated with mitotane monotherapy, the polymorphism of CYP2W1 was associated with a reduced probability of reaching the mitotane therapeutic range and with lower response rates, whereas the polymorphism of CYP2B6 was correlated with high plasma levels of mitotane [28]. It was documented that mitotane is a CYP2B inducer (see section 3.1.3); however, the roles of CYP2B6 and CYP2W1 in mitotane functions are not yet clear. Thus, Kerkhofs and colleagues (2015) [29] proposed a new pharmacokinetic model adapted to individual patients in daily clinical practice. The 3-compartment model was proposed to measure mitotane levels through the volumes of distribution and clearance [29]. Therefore, this model can be used as a tool to elucidate the absorption of mitotane and the variability among patients.

\subsubsection{Distribution}

The distribution of mitotane in various body compartments has been studied for a long time. The estimated volume of distribution was relatively high. Thus, the plasma concentration was more influenced by mitotane distribution than the elimination process [29]. The maximum concentration of mitotane can be detected in the plasma of patients 2-8 hours after a single dose of $2 \mathrm{~g}$ [26]. Nevertheless, DDA levels were higher than mitotane levels in the plasma, whereas DDE was barely detected after the administration of repeated doses [30]. However, the mitotane concentration in adipose tissue was 200-fold higher than the plasma concentration in patients during chemotherapy [31]. In rats, after 80 days of diet containing $1 \%$ mitotane, mitotane tended to accumulate mainly in adipose tissue, as well as in the liver, kidney, brain, and adrenal tissue [32]. Mitotane labeled with ${ }^{14} \mathrm{C}$ was localized mainly in the zona fasciculata and zona reticularis in human adrenocortical tumor and mouse adrenal tissue [33,34]. 
Distribution of mitotane involved chylomicron and lipoprotein binding as a higher proportion of plasma mitotane was bound to lipoproteins [35]. Under normolipidemic conditions, a substantial amount of mitotane was bound to high density lipoprotein and albumin, whereas under hypertriglyceridemic conditions, mitotane was bound mainly to chylomicron and to very low-density lipoproteins (VLDL) [36]. The distribution of mitotane involves cellular diffusion by adhering to LDL. Interestingly, mitotane promoted LDL formation [37], and probably promoted its self-uptake into adrenals cells. However, in vitro, lipoprotein binding inhibited the activity of mitotane, suggesting that lipoprotein-free mitotane was its therapeutically active fraction $[35,38]$. Higher antiproliferative and proapoptotic effects of mitotane were shown in H295R cells grown in lipoprotein-free medium, and a higher rate of tumor control was demonstrated in patients with ACC treated with mitotane and statins [38]. Under hypertriglyceridemic conditions, the bound mitotane-VLDL complex does not enter into the adrenal cells [36], and the patient may be unresponsive to the effects of mitotane. High concentrations of DDA and DDE were also found bound to chylomicrons. However, it is important to note that DDA is not too lipophilic due to the presence of the carboxylic acid group, whereas mitotane and DDE have a high affinity for lipids [35]. Therefore, to estimate toxicity and efficacy and improve patient care, it is important to quantify lipoprotein-free and lipoprotein-bound mitotane [35].

Regarding the enantiomers of mitotane, different elimination ratios were suggested in the exposure of enantiomers to human placentas as measured by gas chromatography [39]. S(-)-o,p'-DDD was dominant in the plasma of two minipigs whereas the enantiomer R-(+)-o,p'-DDD was dominant in the plasma of three minipigs [40]. Besides, the two isomers were equally potent in decreasing H295R cell viability, (S)-(-)-o,p'-DDD affected hormone secretion (dehydroepiandrosterone [DHEA] and cortisol) slightly less than the (R)-(+)o,p'-DDD and the racemic mixture [41]. Thus, it is also suggested that the racemic mixture is important for the therapeutic effects of mitotane. However, the pharmacological features of each enantiomer in ACC treatment are not yet clear.

\subsubsection{Metabolism}

The metabolism of mitotane was previously described as occurring only in adrenal cells [42]. This drug has two reactions in the mitochondria of adrenal cells: $\alpha$-hydroxylation which yields the end-product DDE, and $\beta$-hydroxylation which gives rise to the end-product DDA (Fig. 1B). Although measurements of plasma DDA for estimating the effects of mitotane suggested that it was an active metabolite [30], other authors claimed that DDA was an inactive metabolite [38]. In fact, DDA is not so lipophilic and its presence is further found in the urine (see section 3.1.4), suggesting that DDA is an end-product of the mitotane deactivation pathway. In contrast, it has been speculated that DDE could be an active metabolite, since it was not extensively found in plasma, urine, or feces (see section 3.1.4) and had a cytotoxic effect on the H295R adrenocortical cell line [43]. However, no additional studies have been conducted yet to confirm this hypothesis.

The $\beta$-hydroxylation of mitotane has another important function beyond DDA formation, which is the generation of an intermediate reactive metabolite, an acyl chloride derivative (DDAC), which might be responsible for covalent binding to mitochondrial macromolecules in the adrenals [44]. It is important to point out that the covalent bond is not permanent and can be reversed by the addition of glutathione reductase (GSH), suggesting that GSH can inactivate mitotane [45]. The reaction for the covalent bond is mediated through a specific CYP450 responsible for steroidogenesis in the adrenal cells, such as CYP11A1 (see section 3.2) [46]. In the presence of a P450 inhibitor (erythromycin), mitotane and DDA tend to accumulate in fat tissue and plasma, whereas the levels of DDE decrease [32], supporting the theory that $\mathrm{P} 450$ is responsible for $\alpha$-hydroxylation of mitotane. In addition, accumulation of ${ }^{14} \mathrm{C}$ labeled mitotane in the adrenals was partially reversed by metyrapone, a known inhibitor of CYP11B1 [33,34], suggesting that both CYP11A1 and CYP11B1 are involved in the formation of the DDAC.

Other CYPs are also related to the effects of mitotane. Recently, Murtha and colleagues demonstrated that silencing of CYP2A6 mRNA in H295R cells promoted higher sensitivity of this cell line to the effects of mitotane [47]. This enzyme is a known metabolizer of some xenobiotics; however, the exact function of CYP2A6 in ACC is still unclear. Moreover, high expression level of CYP2W1 mRNA was observed in both normal and neoplastic adrenal glands and was related to a better response to mitotane treatment among 
patients [48]. It was suggested that CYP2W1 might play a role in mitotane metabolism and could be a potential predictive marker of sensitivity to mitotane treatment [49]; however, the tissue expression and function of CYP2W1 are still under debate.

When mitotane was administered to mice, via the intraperitoneal route (440 $\mathrm{mg} \mathrm{kg}^{-1}$, dissolved in olive oil, for 48 days), the antitumor effects remained for 34 days, compared to those achieved by oral administration, which yielded antitumor effects for only 13 days [25]. This suggests that mitotane undergoes first pass metabolism when administered orally and/or is largely eliminated via feces. Furthermore, the intestinal microbiome could also influence mitotane absorption and metabolism. The hypothesis of intestinal mitotane metabolism is supported by high concentrations of DDA and DDE found in chyle. Moreover, DDE might be metabolized further in the liver, which would explain why this compound was barely detected in the plasma [35]. This indicates that mitotane might be metabolized in the liver via enzymatic (i.e. via CYP450) and non-enzymatic (i. e., glutathione [GSH]) reactions since DDT is metabolized in the liver in the same way [50]. However, no preclinical studies have investigated the metabolism of mitotane, DDA, and DDE in the liver. Moreover, the role of the intestinal microbiome in mitotane metabolism should also be considered, since the gut microbiota plays a role in drug metabolism prior to absorption or during enterohepatic circulation, via various microbial enzymatic reactions in the intestine [51]. Therefore, understanding the effects of liver and gut microbiota on mitotane metabolism is crucial to explaining the changes in its pharmacokinetics.

Mitotane has a narrow therapeutic index; thus, the possibility of pharmacokinetic drug-drug interactions should not be discarded. This drug has a long-lasting inducing effect on CYP3A4 and CYP2B and a potent inhibitory effect on CYP2C19, which result in clinical interactions with many drugs metabolized by these enzymes $[52,53,54]$. Therefore, when associative treatment of mitotane in combination with such drugs (i.e. doxorubicin, etoposide, hydrocortisone, cyclophosphamide, omeprazole, and clopidogrel) is necessary, the therapeutic effects and toxicity of these drugs need to be monitored closely.

\subsubsection{Elimination}

After an oral intake of a single mitotane dose in tablet form $(2 \mathrm{~g})$, around $40 \%$ of unchanged mitotane could be detected in the feces after $12 \mathrm{~h}$, whereas mitotane in milk or emulsion decreased the amount of drug excreted to less than 10\% [26]. Furthermore, after oral mitotane treatment (100 mg) in rats, $7.1 \%$ was excreted in the urine and $87.8 \%$ of mitotane was found in the feces within 8 days [55]. Thus, unchanged mitotane appears to be eliminated largely through biliary excretion. However, mitotane, DDA, and DDE can also undergo enterohepatic circulation; chyle could be enriched due to hepatic transformation [35]. The mitotane clearance and volume of distribution in the steady state were determined in 22 patients as 0.94 $\pm 0.37 \mathrm{~L} \mathrm{~h}^{-1}$ and $161 \pm 68 \mathrm{~L} \mathrm{~kg}^{-1}$ of the lean body mass, respectively [29]. In addition, DDA was found in the urine of mice treated with mitotane $\left(250 \mathrm{mg} \mathrm{kg}^{-1}\right.$, p.o.) for a total of $96 \mathrm{~h}$ [24] as well as in the feces [56]. Although renal elimination also plays an important role in mitotane clearance, the rate is lower than that of biliary elimination. In a study of 19 patients receiving mitotane at $3-6 \mathrm{~g}^{-1 a y^{-1}}$ over a period of 30-60 days, the half-life was found to be between 18 and 159 days after mitotane was withdrawn [26]. Long-term mitotane elimination observed was probably due to its accumulation in fat tissue, attributable to its lipophilic characteristics.

\subsection{Pharmacodynamics and pharmacological effects}

The main effect of mitotane in ACC is to decrease steroid production, such as androgens (DHEA) and cortisol, and induce tumor cellular death $[6,10]$. The current recommendation is to maintain the plasma level higher than $7 \mathrm{mg} \mathrm{L}^{-1}(>21.8 \mu \mathrm{M})$ to produce anti-steroidogenic effects and between 14-20 $\mathrm{mg} \mathrm{L}^{-1}(43.7-62.5$ $\mu \mathrm{M})$ for antitumor effects [30,57]. The major findings on the mechanism of action of mitotane were firstly reported in dogs and mice, besides reports suggesting that rodents were more insensitive to antisecretory mitotane effects $[25,44,42]$. The mechanism of action of mitotane takes place mainly in adrenal mitochondria and can be divided into four major categories: (i) inhibition of steroidogenesis, (ii) endoplasmic reticulum (ER) stress, (iii) cell death, and (iv) others (Fig. 2)

Inhibition of steroidogenesis 
It is known that the rate-limiting step in steroidogenesis is the transport of cholesterol from the outer mitochondrial membrane to the inner mitochondrial membrane through the enzyme CYP11A1 (Fig. 3). Cholesterol reaches CYP11A1 via the transduceosome, a multiple protein complex in the mitochondrial membrane, that contains the translocator protein/peripheral-type benzodiazepine receptor or sigma 1 receptor (TSPO), steroidogenic acute regulatory protein (StAR), ATPase family AAA domain-containing protein 3A (ATAD3A), and voltage-dependent anion channel (VDAC) [58]. Interestingly, incubation with TSPO inhibitor in combination with mitotane significantly potentiated the antitumor and antisecretory actions of mitotane in H295R cells [59]. In addition, the expression of protein kinase A regulatory subunit (PRKAR1A ), which is involved in the activation of steroidogenesis, was reduced following $24 \mathrm{~h}$ of treatment with mitotane [46]. This confirms that mitotane binds specifically to CYP11A1.

Many years ago, it was suggested that mitotane produced reactive metabolites, such as DDAC, via mitotane $\beta$-hydroxylation through CYP450, which could covalently bind to mitochondrial macromolecules $[44,60]$. Later, this hypothesis was confirmed when mitotane was found to bind to the mitochondria in bovine and dog adrenals and to phospholipids and proteins in the liver and lung of mice [45]. Mitotane labeled with ${ }^{14} \mathrm{C}$ was found to bind to the zona fasciculata / zona reticularis in adrenocortical tumor and mouse adrenals, which was partially reversed by metyrapone, a known inhibitor of CYP11B1 [33,34]. These data suggest that CYP11B1 may also result in the formation of reactive species. CYP11B1 is localized in the mitochondrial inner membrane and is involved in the conversion of progesterone to cortisol in the adrenal cortex (NCBI database gene). In addition, CYP21A2, CYP17A1, hydroxy-delta-5-steroid dehydrogenase 3 beta- and steroid delta-isomerase type 1 (HSD3B1), and type 2 (HSD3B2) were also found to be decreased in cells after incubation with mitotane $[46,61]$. The inhibition of these enzymes results in reduction in aldosterone, cortisol, DHEA, testosterone, and estradiol production, reducing ACC symptoms.

Considering that the aforementioned CYPs are steroidogenic enzymes localized mainly in the adrenals, it may explain partially why mitotane has local effect on adrenal tissue. However, until now, there is a lack of studies that assessed the DDAC bound to macromolecules in human adrenal and liver cells, to support this hypothesis. In addition, the involvement of other reactive intermediates such as epoxides and free radicals should also be considered in elucidating the mechanisms of mitotane action [45].

The adrenocortical cell line is more sensitive to mitotane $\left(\mathrm{EC}_{50}=18.1 \mu \mathrm{M}\right)$ whereas the $\mathrm{EC}_{50}$ was 3 -fold lower in HeLa, HepG2, HEK293, and IMR32 cells [62]. This supports the idea that mitotane specifically affects the steroidogenesis pathways in adrenocortical cells. However, it is still unclear whether mitotane inhibits a key enzyme, such as CYP11A1, resulting in reductions in several steroidogenic enzymes; inhibits a steroidogenic regulatory gene, such as $S R E B F$ (see below); or if mitotane affects all the steroidogenic enzymes simultaneously. Additional studies evaluating the chemical reaction between the intermediate metabolite DDAC and adrenal mitochondrial compounds are still needed to assess if it occurs with specific enzymes.

\section{Endoplasmic reticulum (ER) stress}

Mitotane inhibited the function of sterol- $O$-acyl transferase 1 (SOAT1) in H295R cells which highly express this enzyme [62]. SOAT1 is an intracellular protein located in the ER that promotes the formation of fatty acid-cholesterol esters (NCBI database gene). The suppression of SOAT1 by mitotane led to an accumulation of free cholesterol and fatty acids, which explains why patients had an increase in cholesterol level throughout mitotane treatment [63]. This increase in free cholesterol ester and fatty acid levels induced ER stress promoting downregulation of sterol regulatory element-binding transcription factor 1 (SREBF) [62].SREBF is a gene that stimulates the transcription of steroid-regulated genes (NCBI database gene); thus, the inhibition of steroid production induced by mitotane may be due to the downregulation of $S R E B F$ . As ER stress persisted, it induced the expression of protein kinase R-like endoplasmic reticulum kinase (PERK) which phosphorylated the eukaryotic initiation factor $2 \alpha$ phosphorylation (eIF2 $\alpha$ ) and activated the $\mathrm{C} / \mathrm{EBP}$ homologous protein (CHOP) expression. The upregulation of CHOP activated the intrinsic apoptosis pathway, leading to cellular death [62]. Therefore, the inhibition of the $S R E B F$ gene through ER stress may underlie one of the mechanisms by which mitotane induces the activity of caspases and the reduction in steroid production on ACC. In this line, a novel SOAT1 inhibitor (ATR-101, PD132301-2, nevanimibe 
$\mathrm{HCl}$ ) was demonstrated to induce ER stress and apoptosis in adrenal cells [64]. Thus, a recent multicenter phase 1 study was conducted to assess the safety and pharmacokinetics (PK) of nevanimibe in adults with metastatic ACC. Although no patients experienced a complete or partial response, $27 \%$ of the patients had stable disease. However, given that the expected exposure levels necessary for an apoptotic effect could not be achieved with the maximum feasible dose, the current formulation of nevanimibe had limited efficacy in patients with advanced ACC [65].

\section{Cell death}

The attachment of the DDAC to adrenal cells can either induce oxidative stress and cellular death by apoptosis and/or necroptosis. It was also found that the decrease in adrenal cell viability was due to increase in caspase 3/7 activity, which induced cellular apoptosis [46]. Moreover, the apoptosis was also due to inhibition of mitochondrial respiratory chain complexes I and IV in H295R cells by inducing cytochrome c oxidase defect [66]. It has been observed that mitotane $(30$ and $50 \mu \mathrm{M})$ induced mitochondrial morphological alterations in human tumor adrenocortical cells (H295R and SW13), including membrane disruption, affecting respiratory chain enzymes, such as succinate dehydrogenase and the voltage-dependent anion channel, resulting in inhibition of tumor cell proliferation and induction of cellular apoptosis [66,67]. Despite the evidence that adrenal cortical cells were also susceptible to ferroptosis dependent on steroid pathways, mitotane did not induce this form of cell death in ACC cells [68].

\section{Other mechanisms}

In addition to inhibition of steroidogenesis, ER stress, and apoptosis, mitotane also alters other pathways that need further investigations. Mitotane modulates proteins involved in cellular metabolism (NADPH), stress response (peroxiredoxin I, II, and VI and heat shock protein 27), cytoskeleton structure (tubulin-b isoform II and profilin-1), and tumorigenesis (prohibitin, heterogenous nuclear ribonucleoprotein A2/B1, and cathepsin D). These proteins represent good targets for the development of strategies that can directly inhibit ACC growth [69]. Moreover, mitotane inhibited the expression of transforming growth factor $\beta 1$ (TGF- $\beta$ ) gene, encoding a potent inhibitor of cell proliferation and steroidogenesis. However, it appeared to be independent of CYP11A1 or CYP11B1 inhibition [46].

Despite the evidence that mitotane affects the aforementioned pathways, the molecular mechanisms of acquired mitotane resistance are currently unknown. Thus, a recent study established an in vitro model of mitotane resistance in ACC using the HAC-15 cell line. The findings showed an absence of mitochondrial damage and increased in intracellular free cholesterol levels, downregulation of adrenal steroids production, and regulation of extracellular-signal-regulated kinase (ERK), apoptotic cell clearance, and response to xenobiotics in mitotane-treated resistant cells, compared to that in nonresistant controls. The study pointed at the changes in lipoprotein and lipid homeostasis which collectively may contribute to the resistant phenotype. Although this model might help develop strategies to overcome mitotane resistancein vitro, further studies should be performed using in vivo models of mitotane resistance before conducting clinical trials [70].

\section{Toxicity}

Mitotane concentrations above $20 \mathrm{mg} \mathrm{L}^{-1}$ are highly toxic. The oral $\mathrm{LD}_{50}$ of mitotane were reported to be 17, 5, 4, and $5 \mathrm{~g}$ in humans, guinea pigs, mice, and rats, respectively (NIH-TOXNET; ChemIDplus). Even though plasma mitotane levels are maintained below $20 \mathrm{mg} \mathrm{L}^{-1}$ for ACC treatment, patients with plasma levels $<15 \mathrm{mg} \mathrm{L}^{-1}$ can experience several toxic effects, probably due to the variability in CYP activity among patients.

The most common side effects of mitotane are unspecific, such as those involving the gastrointestinal, nervous, and endocrine systems, and can vary among patients. The unspecific gastrointestinal symptoms include diarrhea, nausea, vomiting, and anorexia, which can evolve to mucositis $[71,21,10]$. These symptoms were reported in $78 \%$ of patients who received daily doses of $2 \mathrm{~g}$ or more [72]. At higher doses, mitotane affected the central nervous system and produced neuromuscular manifestations, including ataxia, speech disturbance, confusion, somnolence, depression, decrease memory, muscle tremors, polyneuropathy, and dizziness [72]. 
Mitotane increased hepatic production of sex hormone binding globulin (i.e human corticosteroid-binding globulin $[\mathrm{CBG}]$, sex hormone binding globulin [SHBG], thyroxine-binding globulin [TBG], and vitamin D binding protein) and cortisol binding globulin, which increased total serum levels of gonadal steroids and cortisol. Thus, the androgen-synthesis reducing effect of mitotane and a relative increase in SHBG may cause gynecomastia and primary hypogonadism $[71,10,2]$. Mitotane treatment may also increase bilirubin levels and skin rashes $[37,71]$.

An increase in cholesterol levels was also documented during mitotane administration. Mitotane's inhibition of CYP450, an enzyme involved in cholesterol metabolites formation, may result in an increase in mevalonic acid and oxysterols responsible for downregulating hepatic cholesterol synthesis [37]. However, the exact effect of the increase in the activity of the mevalonate pathway during mitotane treatment is not well explored. Mitotane also influenced the production of thyroid hormones, leading to a decrease in the levels of thyroid-stimulating hormone and free thyroxine, which must be monitored and replaced if necessary [71]. Other manifestations included impotence, thrombocytopenia, anemia, and increases in hepatic enzyme levels $[71,10]$. Recently, dyspnea was also reported in a female patient [73]. In general, adverse events were reversible after the cessation of mitotane treatment [71]. Because mitotane may effectively decrease the synthesis of all steroids, it is mandatory that clinicians consider the need to prescribe glucocorticoid and mineralocorticoid replacements. This concern is more urgent in tumors presenting with high levels of glucocorticoids, suppression of the hypothalamus-pituitary-adrenal-axis, and potential acute or chronic adrenal insufficiency. Mitotane may aggravate adrenal cortex suppression. Taken together, mitotane toxicity may limit tolerability, and it may be necessary to discontinue treatment.

\section{New perspectives for mitotane treatment}

To improve the current therapeutic options for ACC with less toxic effects, the development of new formulations containing mitotane or new compounds containing its metabolites should be an attractive option. Below we discuss two potential options for ACC treatment.

\section{$\mathrm{MeSO}_{2}$-DDE (3-methylsulfonyl-2,2-bis(4-chloro-[14C]phenyl)-1,1-dichloroethene $\mathrm{MeSO}_{2}$-[14C]DDE)}

$\mathrm{MeSO}_{2}$-DDE is a synthetic compound derived from DDE and aryl methyl sulfones. $\mathrm{MeSO}_{2}$-DDE is selectively taken up and covalently bound in the zona fasciculata in adrenal cortex in mice [74]. $\mathrm{MeSO}_{2}$-DDE is a potent adrenocorticolytic agent at the lower doses than mitotane in humans [34]. Similar to mitotane, $\mathrm{MeSO}_{2}$-DDE generated a reactive intermediate metabolite by binding to CYP11B1, mitochondrial degeneration, and cell death in the murine adrenal cortex [34]. In murine adrenocortical Y-1 tumor cells, both mitotane and $\mathrm{MeSO}_{2}$-DDE inhibited corticosterone production, but only $\mathrm{MeSO}_{2}$-DDE was cytotoxic. The cytotoxicity was inhibited by the potent CYP11B1 inhibitor etomidate, suggesting that CYP11B1 plays a role in this effect of $\mathrm{MeSO}_{2}$-DDE [75,76]. In addition, $\mathrm{MeSO}_{2}$-DDE inhibited cortisol production in $\mathrm{H} 295 \mathrm{R}$ cells, but did not affect aldosterone secretion [77]. On the other hand, in H295R cells $(5-15 \mu \mathrm{M})$ and in a nude mice xenograft model (50 mg kg-1, i.p.), mitotane was more cytotoxic than $\mathrm{MeSO}_{2}$-DDE [78]. The concentration and dose of $\mathrm{MeSO}_{2}$-DDE are important factors since at low concentrations it can stimulate steroid production and CYP11B1 expression, and at higher concentrations it has the opposite effect [79]. Investigation using minipigs showed that the plasma, fat, and liver concentrations of $\mathrm{MeSO}_{2}$-DDE were, respectively, 2-, 25-, and 18-fold higher than those of mitotane. Likewise, the rate of elimination was slow, and this might be a challenge to designing appropriate dosages for patients [76]. Overall, $\mathrm{MeSO}_{2}$-DDE may represent a potential alternative for the treatment of ACC, and further clinical studies are encouraged.

\section{Nano-formulations}

Nano-formulations have emerged as an attractive strategy for incorporation in lipid molecules that have poor water solubility, such as mitotane. Mitotane nano-formulations are expected to improve the therapeutic effect, enhance bioavailability, and reduce the toxic effects of mitotane [80]. Three formulations are being developed:(i) self-microemulsifying drug delivery system (SMEDDS),(ii) lipid-based nanocarriers, and (iii) micelles. 
(i) SMEDDS: SMEDDS is an approach to incorporating lipid molecules. Preconcentrated microemulsion is useful for enhancing the dissolution rate of poorly water-soluble drugs and increasing bioavailability [81]. The formulation mitotane-SMEDDS contains Capryol ${ }^{\circledR}$, Tween ${ }^{\circledR}$, and Cremophor ${ }^{\circledR}$ at the same concentrations. SMEDDS was found to cross the intestinal barrier much faster than a solution of mitotane, with a bioavailability of 3.4\% [82]. However, no studies have been performed yet to evaluate if SMEDDS can also decrease gastrointestinal toxicity, which occurs due to the poor solubility of mitotane in the gastrointestinal system. Moreover, there is a lack of preclinical studies, including in vitro and in vivoobservations, to investigate whether SMEDDS could enhance the antisecretory and antitumor effects in ACC. Nevertheless, SMEDDS can be considered as a new tool for optimizing the administration of mitotane and additional studies should be performed in this regard.

(ii) Lipid-based nanocarriers: Solid lipid nanoparticles (SLNs) or nanostructured lipid carriers (NLCs) consist of either solid or lipid nanoparticles. NLCs are a novel type of lipid nanoparticles that use a solid matrix [80]. In fact, mitotane was efficiently loaded in SLNs and in NLCs, as potential delivery systems for enhancing the therapeutic effects of mitotane, improving bioavailability, and controlling drug release [83]. However, no additional studies have been carried out yet to evaluate the efficacy of nano-formulations in ACC.

(iii) Micelles: Micelles are promising nanocarrier systems for drug delivery, especially for antitumor agents [84]. Polymeric micelles are structures formed by an arrangement of amphiphilic copolymers in aqueous solutions [85]. The advantages of this nano-formulation are control of drug release, tissue-penetrating ability, and reduced toxicity [84]. As mitotane has poor solubility in water and consequently in plasma, Haider and colleagues [86] developed a micelle poly(2-methyl-2-oxazoline)-block-poly(2-butyl-2-oxazoline)-block-poly(2methyl-2-oxazoline) (pMeOx-pBuOx-pMeOx) based mitotane nano-formulation with high drug loading. Micellar mitotane exhibits comparable efficacy with its ethanol equivalent, suggesting that this nano-formulation is suitable for intravenous administration and may improve mitotane plasma concentration and consequently the efficacy. Additional studies about the safety and tolerability of this injectable formulation are warranted [86].

\section{Conclusion and future directions}

Mitotane is the only drug approved for ACC treatment since there is a lack of new compounds with specific antisecretory and antitumor effects. However, its pharmacokinetic features do not make mitotane an ideal drug for ACC because of its very poor absorption. In addition, the polymorphism of CYPs may also be involved in the variability of the therapeutic effect of mitotane among patients. Consequently, high doses are employed, inducing several side effects. Although the mechanism of action is not well elucidated, there is evidence that mitotane might control steroid production and induce apoptosis through ER stress and inhibition of mitochondrial respiration. The formation of reactive species during $\beta$-hydroxylation, such as DDAC, should also be considered in the mechanism of mitotane action, as this can lead to the acylation of cellular molecules and induce cell death. Furthermore, the ability of mitotane to bind to adrenal mitochondria via steroidogenic enzymes (i.e. CYP11B1 and CYP11A1) suggest that mitotane is metabolized in the adrenals. However, the pharmacokinetics and exact mechanisms of action of mitotane still need to be thoroughly clarified to understand the variability of the pharmacokinetic and therapeutic effects among patients.

New formulations or compounds containing mitotane or its metabolites can be an attractive option to improve chemotherapy treatment and decrease mitotane toxicity. Nano-formulations are currently the most studied option, since they can apparently enhance bioavailability, adrenal drug delivery, and decrease side effects, mainly in the gastrointestinal system. There are only few studies evaluating new formulations of mitotane. Therefore, it is necessary to conduct new studies in this field to improve ACC treatment. Despite this, due to the antisecretory and antitumor effects of mitotane in adrenal tumor cells, it continues to be the drug of choice for improving the survival of patients with ACC.

\section{Acknowledgements}

The authors thanks to Instituto de Pesquisa Pelé Pequeno Príncipe, Curitiba-PR, and the Brazilian funding 
agencies: Conselho Nacional de Desenvolvimento Científico e Tecnológico (CNPq); Fundação Araucária-PR; and Coordenação de Aperfeiçoamento de Pessoal de Nível Superior (CAPES) [Finance code 001].

\section{Conflict of Interest}

The authors declare no conflicts of interest.

\section{References}

1. Michalkiewicz E, Sandrini R, Figueiredo B, et al. Clinical and outcome characteristics of children with adrenocortical tumors: A report from the International Pediatric Adrenocortical Tumor Registry. J Clin Oncol 2004; 22: 838-845.

2. Else T, Kim AC, Sabolch A, et al. Adrenocortical carcinoma. Endocr Rev 2014; 35: 282-326. https://doi: 10.1210/er.2013-1029

3. Custódio G, Parise GA, Kiesel Filho N, et al. Impact of Neonatal Screening and Surveillance for the TP53 R337H Mutation on Early Detection of Childhood Adrenocortical Tumors. J Clin Oncol 2013; 31: 2619-2626.

4. Allolio B, Fassnacht M. Adrenocortical carcinoma, In: Grossman, A.P. Endocrinology Adult and pediatric, The adrenal gland. sixth ed. Philadelphia: Elsevier; 2010, pp. e168.

5. Mauclère-Denost S, Leboulleux S, Borget I, et al. High-dose mitotane strategy in adrenocortical carcinoma: prospective analysis of plasma mitotane measurement during the first 3 months of follow-up. Eur J Endocrinol 2012; 166: 261-268. https://doi.org/10.1530/EJE-11-0557

6. Zancanella P, Pianovski MA, Oliveira BH, et al. Mitotane Associated with cisplatin, etoposide, and doxorubicin in advanced childhood adrenocortical carcinoma. J Pediatr Hematol Oncol 2006; 28: 513-524. https://doi.org/10.1097/01.mph.0000212965.52759.1c

7. Berruti A, Terzolo M, Pia A, et al. Mitotane associated with etoposide, doxorubicin, and cisplatin in the treatment of advanced adrenocortical carcinoma. Italian Group for the Study of Adrenal Cancer. Cancer 1998; 83: 2194-2000.

8. Pereira RM, Michalkiewicz E, Sandrini F, et al. Childhood Adrenocortical Tumors: A Review. Arq Bras Endocrinol Metabol 2004; 48: 651-658.

9. Terzolo M, Pia A, Berruti A, et al. Low-dose monitored mitotane treatment achieves the therapeutic range with manageable side effects in patients with adrenocortical cancer. J Clin Endocrinol Metab 2000; 85: 2234-2238. https://doi.org/10.1210/jcem.85.6.6619

10. Daffara F, De Francia S, Reimondo G, et al. Prospective evaluation of mitotane toxicity in adrenocortical cancer patients treated adjuvantly. Endocr Relat Cancer 2008; 15: 1043-1053. https://doi.org/10.1677/ERC08-0103

11. Nelson AA, Woodard G. Severe adrenal cortical atrophy (cytotoxic) and hepatic damage produced in dogs by feeding 2,2-bis(parachlorophenyl)-1,1-dichloroethane (DDD or TDE). Arch Pathol (Chic) 1949; 48: 387-394.

12. Nichols J, Green HD. Effect of DDD Treatment on Metabolic Response of Dogs to ACTH Injection. Am J Physiol 1954; 176: 374-376. https://doi.org/10.1152/ajplegacy.1954.176.3.374

13. Bergenstal DM, Lipsett MB, Moy RH, et al. Regression of adrenal cancer and suppression of adrenal function in men by o,p'-DDD. Trans Assoc Am Physicians 1959; 72: 341. https://doi.org/10.1016/B978-14832-2866-2.50035-0

14. Waszut U, Szyszka P, Dworakowska D. Understanding mitotane mode of action. J Physiol Pharmacol 2017; 68: 13-26. 
15. Megerle F, Kroiss M, Hahner S, et al. Advanced Adrenocortical Carcinoma - What to do when First-Line Therapy Fails?. Exp Clin Endocrinol Diabetes 2018; 127: 109-116. https://doi.org/10.1055/a-0715-1946

16. Puglisi S, Calabrese A, Basile V, et al. New perspectives for mitotane treatment of adrenocortical carcinoma. Best Pract Res Clin Endocrinol \& Metab 2020; 101415.

17. Tang Y, Liu Z, Zou Z, et al. Benefits of Adjuvant Mitotane after Resection of Adrenocortical Carcinoma: A Systematic Review and Meta-Analysis. Biomed Res Int 2018; 9362108. https://doi.org/10.1155/2018/9362108

18. Fassnacht M, Terzolo M, Allolio B, et al. FIRM-ACT Study Group, Combination chemotherapy in advanced adrenocortical carcinoma. N Engl J Med 2012; 366: 189-197.

19. Abraham J, Bakke S, Rutt A, et al. A phase II trial of combination chemotherapy and surgical resection for the treatment of metastatic adrenocortical carcinoma: continuous infusion doxorubicin, vincristine, and etoposide with daily mitotane as a P-glycoprotein antagonist. Cancer 2002; 94: 2333-2343.

20. Le Tourneau C, Hoimes C, Zarwan C, et al. Avelumab in patients with previously treated metastatic adrenocortical carcinoma: Phase 1b results from the JAVELIN solid tumor trial. J Immunother Cancer 2018; 6: 111.

21. Berruti A, Terzolo M, Sperone P, et al. Etoposide, doxorubicin and cisplatin plus mitotane in the treatment of advanced adrenocortical carcinoma: A large prospective phase II trial. Endocr Relat Cancer 2005; 12: 657-666.

22. Bukowski RM, Wolfe M, Levine HS, et al. Phase II Trial of Mitotane and Cisplatin in Patients With Adrenal Carcinoma: A Southwest Oncology Group Study. J Clin Oncol 1993; 11: 161-165.

23. Williamson SK, Lew D, Miller GJ, et al. Phase II Evaluation of Cisplatin and Etoposide Followed by Mitotane at Disease Progression in Patients with Locally Advanced or Metastatic Adrenocortical Carcinoma: a Southwest Oncology Group Study. Cancer 2000; 88: 1159-1165.

24. Gold B, Brunk G. A mechanistic study of the metabolism of 1,1-dichloro-2,2-bis(p-chlorophenyl)ethane (DDD) to 2,2-bis(p-chlorophenyl)acetic acid (DDA). Biochem Pharmacol 1984; 33: 979-982. https://doi.org/10.1016/0006-2952(84)90503-3

25. Doghman M, Lalli E. Lack of long-lasting effects of mitotane adjuvant therapy in a mouse xenograft model of adrenocortical carcinoma. Mol Cell Endocrinol 2013; 381: 66-69. https://doi.org/10.1016/j.mce.2013.07.023

26. Moolenaar AJ, van Slooten H, van Seters AP, et al. Blood Levels of o,p'-DDD Following Administration in Various Vehicles After a Single Dose and During Long-term Treatment. Cancer Chemother Pharmacol 1981; 7: 51-54. https://doi.org/10.1007/bf00258213

27. D'Avolio A, De Francia S, Basile V, et al. Influence of the CYP2B6 polymorphism on the pharmacokinetics of mitotane. Pharmacogenet Genomics 2013; 23: 293-300. https://doi.org/10.1097/FPC.0b013e3283606cb2

28. Altieri B, Sbiera S, Herterich S, et al. Effects of Germline CYP2W1*6 and CYP2B6*6 Single Nucleotide Polymorphisms on Mitotane Treatment in Adrenocortical Carcinoma: A Multicenter ENSAT Study. Cancers (Basel) 2020; 12.

29. Kerkhofs TM, Derijks LJ, Ettaieb H, et al. Development of a Pharmacokinetic Model of Mitotane: Toward Personalized Dosing in Adrenocortical Carcinoma. Ther Drug Monit 2015; 37: 58-65. https://doi.org/10.1097/FTD.0000000000000102

30. Hermsen IG, Fassnacht M, Terzolo M, et al. Plasma Concentrations of o',p'DDD, o',p'DDA, and o',p'DDE as Predictors of Tumor Response to Mitotane in Adrenocortical Carcinoma: Results 
of a Retrospective ENS@T Multicenter Study. J Clin Endocrinol Metab 2011; 96: 1844-1851. https://doi.org/10.1210/jc.2010-2676

31. von Slooten H, van Seters AP, Smeenk D, et al. O,p'-DDD (mitotane) levels in plasma and tissues during chemotherapy and at autopsy. Cancer Chemother Pharmacol 1982; 9: 85-88. https://doi.org/10.1007/bf00265384

32. De Francia S, Pirro E, Zappia F, et al. A new simple HPLC method for measuring mitotane and its two principal metabolites Tests in animals and mitotane-treated patients. J Chromatogr B Analyt Technol Biomed Life Sci 2006; 837: 69-75. https://doi.org/10.1016/j.jchromb.2006.04.005

33. Lindhe O, Lund BO, Bergman A, et al. Irreversible Binding and Adrenocorticolytic Activity of the DDT Metabolite 3-Methylsulfonyl-DDE Examined in Tissue-Slice Culture. Environ Health Perspect 2001; 109: 105-110. https://doi.org/10.1289/ehp.109-1240628

34. Lindhe O, Skogseid B, Brandt I. Cytochrome P450-Catalyzed Binding of 3-Methylsulfonyl-DDE and o,p'-DDD in Human Adrenal Zona fasciculata/Reticularis . J Clin Endocrinol Metab 2002; 87: 1319-1326. https://doi.org/10.1210/jcem.87.3.8281

35. Kroiss M, Plonné D, Kendl S, et al. Association of mitotane with chylomicrons and serum lipoproteins: practical implications for treatment of adrenocortical carcinoma. Eur J Endocrinol 2016; 174: 343-353. https://doi.org/10.1530/EJE-15-0946

36. Gebhardt DO, Moolenaar AJ, van Seters AP, et al. The distribution of o,p'-DDD (Mitotane) among serum lipoproteins in normo- and hypertriglyceridemia. Cancer Chemother Pharmacol 1992; 29: 331-334. https://doi.org/10.1007/bf00685956

37. Maher VM, Trainer PJ, Scoppola A, et al. Possible mechanism and treatment of o,p'DDD-induced hypercholesterolaemia. Q J Med 1992; 84: 671-679. https://doi: 10.1093/oxfordjournals.qjmed.a068705

38. Hescot S, Paci A, Seck A, et al. The Lack of Antitumor Effects of o,p'-DDA Excludes Its Role as an Active Metabolite of Mitotane for Adrenocortical Carcinoma Treatment. Horm Cancer 2014; 5: 312-323. https://doi.org/10.1007/s12672-014-0189-7

39. Shen H, Virtanen HE, Main KM, et al. Enantiomeric ratios as an indicator of exposure processes for persistent pollutants in human placentas. Chemosphere 2006; 62: 390-395. https://doi: 10.1016/j.chemosphere.2005.04.100

40. Cantillana T, Lindstrom V, Eriksson L, et al. Interindividual differences in o,p'-DDD enantiomer kinetics examined in Gottingen minipigs. Chemosphere 2009; 76: 167-172. https://doi: 10.1016/j.chemosphere.2009.03.050

41. Asp V, Cantillana T, Bergman A, et al. Chiral effects in adrenocorticolytic action of o,p'-DDD (mitotane) in human adrenal cells. Xenobiotica 2010; 40: 177-183. https://doi.org/10.3109/00498250903470230

42. Martz F, Straw JA. Metabolism and covalent binding of 1-(o-chlorophenyl)-1-(p-chlorophenyl)-2,2dichloroethane (o,p'-DDD). Correlation between adrenocorticolytic activity and metabolic activation by adrenocortical mitochondria. Drug Metab Dispos 1980; 8: 127-130. https://doi.org/10.1124/dmd.8.3.127

43. Germano A, Rapa I, Volante M, et al. RRM1 modulates mitotane activity in adrenal cancer cells interfering with its metabolization. Mol Cell Endocrinol 2015; 401: 105-110. https://doi.org/10.1016/j.mce.2014.11.027

44. Martz F, Straw JA. The in vitro metabolism of 1-(o-chlorophenyl)-1-(p-chlorophenyl)-2,2-dichloroethane (o,p'-DDD) by dog adrenal mitochondria and metabolite covalent binding to mitochondrial macromolecules: a possible mechanism for the adrenocorticolytic effect. Drug Metab Dispos 1977; 5: 482-486.

45. Lund BO, Bergman A, Brandt I. In vitro macromolecular binding of 2-\{2-chlorophenyl $\}-2-\{4$ chlorophenyl $\}$-i,i-dichloroethane (o,p'-DDD) in the mouse lung and liver. Chem Biol Interact 1989; 70: 
63-72. https://doi.org/10.1016/0009-2797(89)90063-x

46. Lehmann TP, Wrzesiński T, Jagodziński PP. The effect of mitotane on viability, steroidogenesis and gene expression in NCI-H295R adrenocortical cells. Mol Med Rep 2013; 7: 893-900. https://doi.org/10.3892/mmr.2012.1244

47. Murtha TD, Brown TC, Rubinstein JC, et al. Overexpression of cytochrome P450 2A6 in adrenocortical carcinoma. Surgery 2017; 161: 1667-1674. https://doi.org/10.1016/j.surg.2016.11.036

48. Ronchi CL, Sbiera S, Volante M, et al. CYP2W1 Is Highly Expressed in Adrenal Glands and Is Positively Associated with the Response to Mitotane in Adrenocortical Carcinoma. PloS One 2014; 9: e105855. https://doi.org/10.1371/journal.pone.0105855

49. Altieri B, Herterich S, Sbiera S, et al. CYP2W1*6 polymorphism as a potential predictive marker of sensitivity to mitotane treatment in adrenocortical carcinoma. Endoc Abstrac 2017; 49: EP161.

50. Kitamura S, Shimizu Y, Shiraga Y, et al. Reductive metabolism of p, p-DDT and o, p-DDT by rat liver cytochrome p450. Drug Metab Dispos 2002; 30: 113-118. https://doi.org/10.1124/dmd.30.2.113

51. Noh K, Kang YR, Nepal NR, et al. Impact of gut microbiota on drug metabolism: an update for safe and effective use of drugs. Arch Pharm Res 2017; 40: 1345-1355. https://doi.org/10.1007/s12272-017-0986-y

52. van Erp NP, Guchelaar HJ, Ploeger BA, et al. Mitotane has a strong and a durable inducing effect on CYP3A4 activity. Eur J Endocrinol 2011; 164: 621-626. https://doi.org/10.1530/EJE-10-0956

53. Theile D, Haefeli WE, Weiss J. Effects of adrenolytic mitotane on drug elimination pathways assessed in vitro. Endocrine 2015; 49: 842-853. https://doi.org/10.1007/s12020-014-0517-2

54. Nims RW, Lubet RA, Fox SD, et al. Comparative pharmacodynamics of CYP2B induction by DDT, DDE, and DDD in male rat liver and cultured rat hepatocytes. J Toxicol Environ Health 1998; 53: 455-477. https://doi.org/10.1080/009841098159187

55. Reif VD, Sinsheimer JE. Metabolism of 1-(0-chlorophenyl)-1-(p-chlorophenyl)-2,2-dichloroethane (o,p'DDD) in rats. Drug Metab Dispos 1975; 3: 15-25.

56. Touitou Y, Bogdan A, Legrand JC, et al. Metabolism of o,p'-DDD (mitotane) in human and animals. Actual notions and practical deductions. Ann Endocrinol (Paris) 1977; 38: 13-25.

57. Lin CW, Chang YH, Pu HF. Mitotane exhibits dual effects on steroidogenic enzymes gene transcription under basal and cAMP-stimulating microenvironments in NCI-H295 cells. Toxicology 2012; 298: 14-23. https://doi.org/10.1016/j.tox.2012.04.007

58. Rone MB, Midzak AS, Issop L, et al. Papadopoulos, Identification of a dynamic mitochondrial protein complex driving cholesterol import, trafficking, and metabolism to steroid hormones. Mol Endocrinol 2012; 26: 1868-1882. https://doi.org/10.1210/me.2012-1159

59. Hescot S, Amazit L, Lhomme M, et al. Identifying mitotane-induced mitochondria-associated membranes dysfunctions: metabolomic and lipidomic approaches. Oncotarget 2017; 8: 109924109940.https://doi.org/10.18632/oncotarget.18968

60. Cai W, Counsell RE, Schteingart DE, et al. Adrenal proteins bound by a reactive intermediate of mitotane. Cancer Chemother Pharmacol 1997; 39: 537-540. https://doi.org/10.1007/s002800050610

61. Zsippai A, Szabó DR, Tömböl Z, et al. Effects of mitotane on gene expression in the adrenocortical cell line NCI-H295R: a microarray study. Pharmacogenomics 2012; 13: 1351-1361. https://doi.org/10.2217/pgs.12.116

62. Sbiera S, Leich E, Liebisch G, et al. Mitotane Inhibits Sterol-O-Acyl Transferase 1 Triggering LipidMediated Endoplasmic Reticulum Stress and Apoptosis in Adrenocortical Carcinoma Cells. Endocrinology 2015; 156: 3895-3908. https://doi.org/10.1210/en.2015-1367 
63. Shawa H, Deniz F, Bazerbashi H, et al. Mitotane-Induced Hyperlipidemia: A Retrospective Cohort Study. Int J Endocrinol 2013; 2013: 624962. https://doi.org/ 10.1155/2013/624962

64. LaPensee CR, Mann JE, Rainey WE, et al. ATR-101, a Selective and Potent Inhibitor of Acyl-CoA Acyltransferase 1, Induces Apoptosis in H295R Adrenocortical Cells and in the Adrenal Cortex of Dogs. Endocrinology 2016; 157: 1775-1788.

65. Smith DC, Kroiss M, Kebebew E, et al. A phase 1 study of nevanimibe $\mathrm{HCl}$, a novel adrenal-specific sterol O-acyltransferase 1 (SOAT1) inhibitor, in adrenocortical carcinoma. Invest New Drugs 2020.

66. Hescot S, Slama A, Lombès A, et al. Mitotane alters mitochondrial respiratory chain activity by inducing cytochrome c oxidase defect in human adrenocortical cells. Endocr Relat Cancer 2013; 20: 371-381. https://doi.org/10.1530/ERC-12-0368

67. Poli G, Guasti D, Rapizzi E, et al. Morphofunctional effects of mitotane on mitochondria in human adrenocortical cancer cells. Endocr Relat Cancer 2013; 20: 537-550. https://doi.org/10.1530/ERC-13-0150

68. Weigand I, Schreiner J, Röhrig F, et al. Active steroid hormone synthesis renders adrenocortical cells highly susceptible to type II ferroptosis induction. Cell Death Dis 2020; 11: 192.

69. Stigliano A, Cerquetti L, Borro M, et al. Modulation of proteomic profile in H295R adrenocortical cell line induced by mitotane. Endocr Relat Cancer 2008; 15: 1-10. https://doi.org/10.1677/ERC-07-0003

70. Seidel E, Walenda G, Messerschmidt C, et al. Generation and characterization of a mitotane-resistant adrenocortical cell line. Endocrinol Connect 2020; 9: 122-134.

71. Allolio B, Fassnacht M. CLINICAL REVIEW: Adrenocortical Carcinoma: Clinical Update. J Clin Endocrinol Metab 2006; 91: 2027-2037.

72. Veytsman I, Nieman L, Fojo T. Management of Endocrine Manifestations and the Use of Mitotane As a Chemotherapeutic Agent for Adrenocortical Carcinoma. J Clin Oncol 2009; 27: 4619-4629.

73. Farooq AU, Amjad W, Kochar T, et al. Mitotane-induced dyspnoea: an unusual side effect. BMJ Case Rep 2018.

74. Lund B, Bergman Â, Brandt I. Metabolic activation and toxicity of a ddtmetabolite, 3methylsulphonyl-dde, in the adrenal zona fascicula ta in mice. Chem Biol Interact 1988; 65: 25-40. https://doi.org/10.1016/0009-2797(88)90028-2

75. Asp V, Lindström V, Olsson JA, et al. Cytotoxicity and decreased corticosterone production in adrenocortical Y-1 cells by 3-methylsulfonyl-DDE and structurally related molecules. Arch Toxicol 2009; 83: 389-396. https://doi.org/10.1007/s00204-008-0342-6

76. Hermansson V, Asp V, Bergman A, et al. Comparative CYP-dependent binding of the adrenocortical toxicants 3-methylsulfonyl-DDE and o,p'-DDD in Y-1 adrenal cells. Arch Toxicol 2007; 81: 793-801. https://doi.org/10.1007/s00204-007-0206-5

77. Ulleras E, Ohlsson A, Oskarsson A. Secretion of cortisol and aldosterone as a vulnerable target for adrenal endocrine disruption - screening of 30 selected chemicals in the human H295R cell model. J Appl Toxicol 2008; 28: 1045-1053. https://doi.org/10.1002/jat.1371

78. Lindhe O, Skogseid B. Mitotane Effects in a H295R Xenograft Model of Adjuvant Treatment of Adrenocortical Cancer. Horm Metab Res 2010; 42: 725-730. https://doi.org/10.1055/s-0030-1261923

79. Asp V, Ulleras E, Lindstrom V, et al. Biphasic hormonal responses to the adrenocorticolytic DDT metabolite 3-methylsulfonyl-DDE in human cells. Toxicol Appl Pharmacol 2010; 242: 281-289. https://doi.org/10.1016/j.taap.2009.10.018 
80. Menaa F, Menaa B. Development of Mitotane Lipid Nanocarriers and Enantiomers: Two-inOne Solution to Efficiently Treat Adreno-Cortical Carcinoma. Curr Med Chem 2012; 19: 5854-5862. https://doi.org/10.2174/092986712804143376

81. Lin $\mathrm{Y}$, Chen $\mathrm{Y}, \mathrm{Wu} \mathrm{T}$, et al. Enhancement of dissolution rate of mitotane and warfarin prepared by using microemulsion systems. Colloids Surf B Biointerfaces 2011; 85: 366-372. https://doi.org/10.1016/j.colsurfb.2011.03.015

82. Attivi D, Ajana I, Astier A, et al. Development of microemulsion of mitotane for improvement of oral bioavailability. Drug Dev Ind Pharm 2010; 36: 421-427. https://doi.org/10.3109/03639040903225083

83. Severino P, Souto EB, Pinho SC, et al. Hydrophilic coating of mitotane-loaded lipid nanoparticles: Preliminary studies for mucosal adhesion. Pharm Dev Technol 2013; 18: 577-581. https://doi.org/10.3109/10837450.2011.614250

84. Nishiyama N, Kataoka K. Current state, achievements, and future prospects of polymeric micelles as nanocarriers for drug and gene delivery. Pharmacol Ther 2006; 112: 630-48.

85. Yadav HKS, Almokdad AA, Shaluf SIM, et al. Nanocarriers for Drug Delivery: Nanoscience and Nanotechnology in Drug Delivery. Amsterdam: Elsevier; 2019, Pages 531-556.

86. Haider MS, Schreiner J, Kendl S, et al. A Micellar Mitotane Formulation with High Drug Loading and Solubility: Physico-Chemical Characterization and Cytotoxicity Studies in 2D and 3D in Vitro Tumor Models. Macromol Biosci 2020; 20: e1900178

Table 1 . Clinical trials on mitotane plus chemotherapy in advanced ACC

\begin{tabular}{|c|c|c|c|c|c|c|c|c|c|c|}
\hline References & $\begin{array}{l}\text { Mean } \\
\text { age } \\
\text { (years) }\end{array}$ & $\begin{array}{l}\text { Number } \\
\text { of } \\
\text { patients }\end{array}$ & Sex & $\begin{array}{l}\text { Treatment } \\
\text { regimen }\end{array}$ & $\begin{array}{l}\text { Duration } \\
\text { of } \\
\text { follow- } \\
\text { up } \\
\text { (months) }\end{array}$ & $\begin{array}{l}\text { Stage of } \\
\text { disease }\end{array}$ & $\begin{array}{l}\text { Mitotane } \\
\text { levels } \\
\left(\mathrm{mg} \mathrm{L}^{-1}\right)\end{array}$ & $\begin{array}{l}\text { Overall } \\
\text { response } \\
\text { rate }\end{array}$ & $\begin{array}{l}\text { Overall } \\
\text { survival } \\
\text { (months) }\end{array}$ & $\begin{array}{l}\text { Disease- } \\
\text { free } \\
\text { survival }\end{array}$ \\
\hline$[20]$ & 50 & 50 & $\begin{array}{l}\text { Male } \\
(\mathrm{n}=24) \\
\text { Female } \\
(\mathrm{n}=26)\end{array}$ & $\begin{array}{l}\mathrm{M}+\mathrm{A} \text { or } \\
\mathrm{A}\end{array}$ & 16.5 & IV & $\begin{array}{l}\text { Not } \\
\text { recorded }\end{array}$ & $\begin{array}{l}\mathrm{M}+\mathrm{A}=48 \% \\
\mathrm{a} \\
\mathrm{A}=48 \% \\
\mathrm{a}\end{array}$ & 610.6 & $\mathrm{NA}$ \\
\hline$[7]$ & 47 & 28 & $\begin{array}{l}\text { Male } \\
(\mathrm{n}=10) \\
\text { Female } \\
(\mathrm{n}=18)\end{array}$ & $\mathrm{M}+\mathrm{E}+\mathrm{D}+$ & QNA & $\begin{array}{l}\text { II }(n=2) \\
\text { III } \\
(n=6) \\
\text { IV } \\
(n=20)\end{array}$ & $\begin{array}{l}\text { Not } \\
\text { recorded }\end{array}$ & $53.5 \%^{\mathrm{b}}$ & NA & NA \\
\hline$[21]$ & 50 & 72 & $\begin{array}{l}\text { Male } \\
(\mathrm{n}=24) \\
\text { Female } \\
(\mathrm{n}=48)\end{array}$ & $\mathrm{M}+\mathrm{E}+\mathrm{D}+$ & $\mathrm{d} 20$ & $\begin{array}{l}\text { I }(n=1) \\
\text { II } \\
(n=24) \\
\text { III } \\
(n=30) \\
\text { IV } \\
(n=17)\end{array}$ & $\begin{array}{l}\text { Not } \\
\text { recorded }\end{array}$ & $48.6 \% \mathrm{~b}$ & $\begin{array}{l}\text { Male }=23.6 \\
\text { Female }=38\end{array}$ & $\begin{array}{l}{[?] 2} \\
6 \text { ears }=26.4 \\
\text { months } \\
{[?] 2} \\
\text { years }=51.7 \\
\text { months }\end{array}$ \\
\hline
\end{tabular}




\begin{tabular}{|c|c|c|c|c|c|c|c|c|c|c|}
\hline References & $\begin{array}{l}\text { Mean } \\
\text { age } \\
\text { (years) }\end{array}$ & $\begin{array}{l}\text { Number } \\
\text { of } \\
\text { patients }\end{array}$ & Sex & $\begin{array}{l}\text { Treatment } \\
\text { regimen }\end{array}$ & $\begin{array}{l}\text { Duration } \\
\text { of } \\
\text { follow- } \\
\text { up } \\
\text { (months) }\end{array}$ & $\begin{array}{l}\text { Stage of } \\
\text { disease }\end{array}$ & $\begin{array}{l}\text { Mitotane } \\
\text { levels } \\
\left(\mathrm{mg} \mathrm{L}^{-1}\right)\end{array}$ & $\begin{array}{l}\text { Overall } \\
\text { response } \\
\text { rate }\end{array}$ & $\begin{array}{l}\text { Overall } \\
\text { survival } \\
\text { (months) }\end{array}$ & $\begin{array}{l}\text { Disease- } \\
\text { free } \\
\text { survival }\end{array}$ \\
\hline$[18]$ & 50 & 304 & $\begin{array}{l}\begin{array}{l}\text { Male } \\
(\mathrm{n}=121) \\
\text { Female } \\
(\mathrm{n}=183)\end{array}\end{array}$ & $\begin{array}{l}\mathrm{M}+\mathrm{E}+\mathrm{D}+ \\
\mathrm{c} \\
\mathrm{M}+\mathrm{SzM}+\mathrm{H} \\
\mathrm{c}\end{array}$ & $\begin{array}{l}\mathrm{CBI}+\mathrm{Sz} \\
\mathrm{E}+\mathrm{D}+\mathrm{C}\end{array}$ & $\begin{array}{l}\text { III } \\
(\mathrm{n}=1) \\
\text { IV } \\
(\mathrm{n}=303)\end{array}$ & 14-20 & $\begin{array}{l}\text { First- } \\
\text { line } \\
\text { therapy: } \\
\mathrm{M}+\mathrm{E}+\mathrm{D}+ \\
\mathrm{a} \\
\mathrm{M}+\mathrm{Sz}=9 . \\
\mathrm{a}\end{array}$ & $\begin{array}{l}\text { First- } \\
\text { line } \\
\text { therapy: } \\
\mathbb{Q} \mathbb{A}=2 \mathrm{~B} \cdot \mathbf{2} 20+ \\
\mathrm{M}+\mathrm{Sz}=12 \\
\%\end{array}$ & $\begin{array}{l}\mathrm{NA} \\
\mathrm{C}=14.8\end{array}$ \\
\hline$[22]$ & 54 & 37 & $\begin{array}{l}\text { Male } \\
(\mathrm{n}=19) \\
\text { Female } \\
(\mathrm{n}=18)\end{array}$ & $\mathrm{M}+\mathrm{C}$ & $\mathrm{NA}$ & IV & $\begin{array}{l}\text { Not } \\
\text { recorded }\end{array}$ & $30 \% \mathrm{~d}$ & 11.8 & NA \\
\hline$[23]$ & 46.5 & 45 & $\begin{array}{l}\text { Male } \\
(\mathrm{n}=23) \\
\text { Female } \\
(\mathrm{n}=22)\end{array}$ & $\begin{array}{l}\mathrm{E}+\mathrm{C} \\
\mathrm{E}+\mathrm{CM} \\
(\mathrm{n}=16) \\
\mathrm{e}\end{array}$ & $\mathrm{NA}$ & $\begin{array}{l}\text { III } \\
(\mathrm{n}=2) \\
\text { IV } \\
(\mathrm{n}=43)\end{array}$ & $\begin{array}{l}\text { Not } \\
\text { recorded }\end{array}$ & $13 \%^{\mathrm{f}}$ & 10 & NA \\
\hline$[19]$ & 44.4 & 36 & $\begin{array}{l}\text { Male } \\
(\mathrm{n}=11) \\
\text { Female } \\
(\mathrm{n}=25)\end{array}$ & $\mathrm{M}+\mathrm{E}+\mathrm{D}+$ & -134.8 & IV & $10-15$ & $22 \%^{\mathrm{g}}$ & 13.5 & NA \\
\hline
\end{tabular}

Table 1: A, avelumab; M, mitotane; E, etoposide; D, doxorubicin; C, cisplatin; Sz, streptozotocin; V, vincristine, NA: not available; ${ }^{\mathrm{a}}$ : Complete + partial response until progressive disease or death; ${ }^{\mathrm{b}}$ : Complete + partial response. Complete response was defined as the disappearance of all clinical evidence of the tumor on physical examination or on radiography and the complete recalcification of all osteolytic metastases for a minimum of 4 weeks. Partial response required at least a $50 \%$ decrease in the measurable tumor size and [?] $50 \%$ recalcification of osteolytic metastases for at least 4 weeks without the appearance of new lesions; ${ }^{c}$ : first-line therapy: $\mathrm{M}+\mathrm{E}+\mathrm{D}+\mathrm{C}$ or $\mathrm{M}+\mathrm{Sz}$; second-line therapy: $\mathrm{M}+\mathrm{E}+\mathrm{D}+\mathrm{CM}+\mathrm{Sz}$ or $\mathrm{M}+\mathrm{SzM}+\mathrm{E}+\mathrm{D}+\mathrm{C}$; ${ }^{\mathrm{d}}$ : Complete + partial response. Complete response was defined as the disappearance of all clinical evidence of the tumor for a minimum of 4 weeks. Partial response required [?] 50\% decrease in the sum of the products of the perpendicular diameters of measured lesions or a decrease [?] $30 \%$ in the sum of liver measurements below

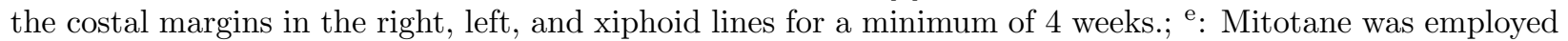
after disease progression following cisplatin and etoposide treatment in patients who had not received prior mitotane treatment; ${ }^{\mathrm{f}}$ : Complete + partial response. Complete response was defined as the disappearance of all clinical evidence of the tumor on at least two successive evaluations. Partial response required a [?] $50 \%$ decrease in the sum of the products of the perpendicular dimensions of all measurable lesions on at least 2 evaluations; ${ }^{\mathrm{g}}$ : Complete + partial + minor response. Complete response was defined as no evidence of measurable disease for a minimum of 4 weeks. Partial response was defined as a [?] $50 \%$ decrease in the sum of the products of the dimensions of all measurable lesions for at least 1 month. Minor response was 
defined as 25-50\% decrease in the sum of the products of the dimensions of all measurable lesions for at least 1 month; Symbols: + combination treatment; change treatment

\section{Figure legends}

Figure 1: Chemical structure of mitotane enantiomers (A) and chemical reaction of mitotane via $\alpha$ - and $\beta$-hydroxylation (B). Legend: o,p'-DDD, mitotane or 1,1-(o,p'-dichlorodiphenyl)-2,2-dichoroethane; o,p'DDE, 1,1-(o,p'- diclorodifenil)-2,2 dicloroetano, o,p'-DDAC, o,p' dichlorodiphenyl acyl chloride; o,p'-DDA, 1,1-(o,p'-dichlorodiphenyl) acetic acid; $\alpha$-OH, $\alpha$-hydroxylation; $\beta$-OH, $\beta$-hydroxylation.

Figure 2: Mechanism underlying the antitumor and antisecretory effects of mitotane (DDD) on adrenal cells. Legend: ABCG1, ATP-binding cassette sub-family G member 1; ADP, adenosine diphosphate; ATP, adenosine triphosphate; Bax, BCL2 associated X apoptosis regulator; Bcl-2, B-cell lymphoma protein 2; CHOP, C/EBP homologous protein; CYP11A1, cytochrome P450 family 11 subfamily A member 1; CYP17A1, cytochrome P450 family 17 subfamily A member 1; CYP21A2, cytochrome P450 family 21 subfamily A member 2; CYP11B1, cytochrome P450 family 11 subfamily B member 1; Cyt c, cytochrome c; DDD, mitotane; ER, endoplasmic reticulum; eIF $2 \alpha$, eukaryotic initiation factor $2 \alpha$ phosphorylation; FAD, flavin adenine dinucleotide; NADH, nicotinamide adenine dinucleotide; PERK, protein kinase R-like endoplasmic reticulum kinase; SOAT1, sterol O-acyltransferase 1; SREBF: sterol regulatory element-binding transcription factor 1. Symbols: activation, inhibition.

Figure 3: Steroidogenic pathway and mitotane (DDD) interaction with specific CYPs. Legend: CYP11A1, cytochrome P450 family 11 subfamily A member 1; CYP17A1, cytochrome P450 family 17 subfamily A member 1; CYP21A2, cytochrome P450 family 21 subfamily A member 2; CYP19A2, cytochrome P450 family 19 subfamily A member 2; CYP11B1, cytochrome P450 family 11 subfamily B member 1; CYP11B2, cytochrome P450 family 11 subfamily B member 2; DDD, mitotane; DHEA, dehydroepiandrosterone; HSD3B2, hydroxy-delta-5-steroid dehydrogenase 3 beta- and steroid delta-isomerase type 2; HSD173B, hydroxy-delta5 -steroid dehydrogenase 17 beta- and steroid delta-isomerase; SRD5A2, 3-oxo-5 $\alpha$-steroid 4-dehydrogenase 2;

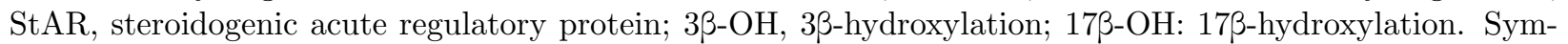
bols: activation, inhibition.

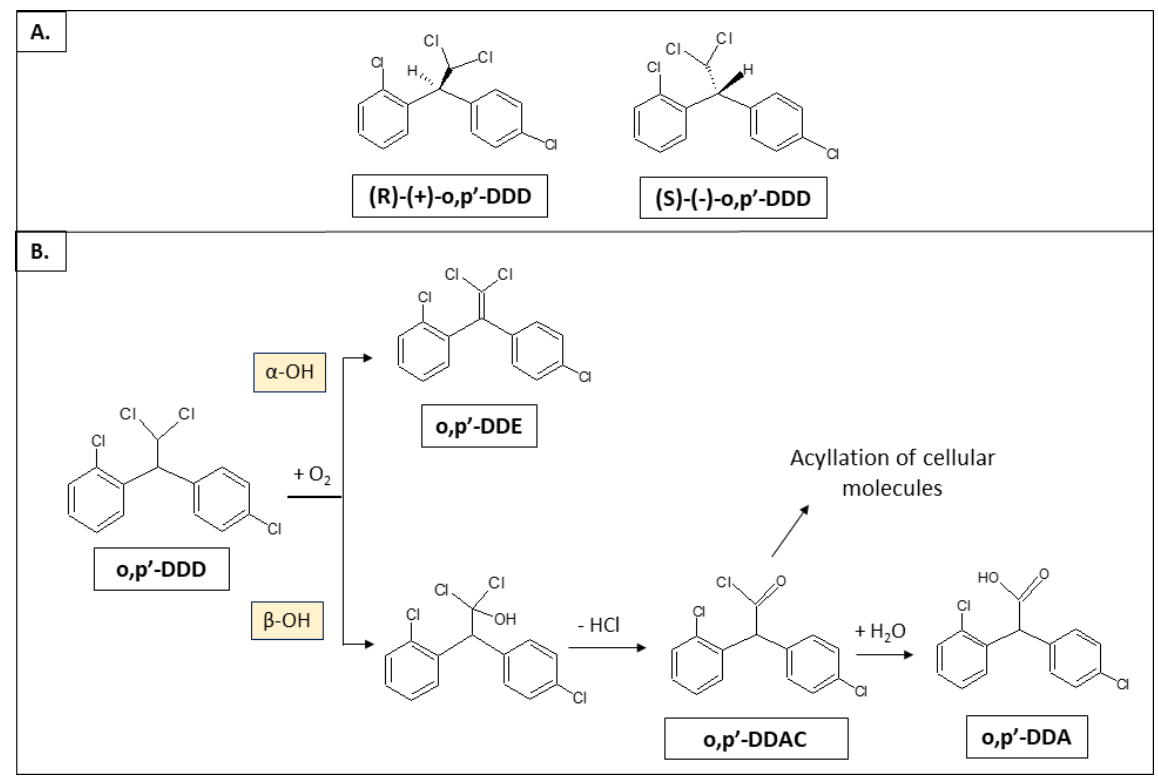



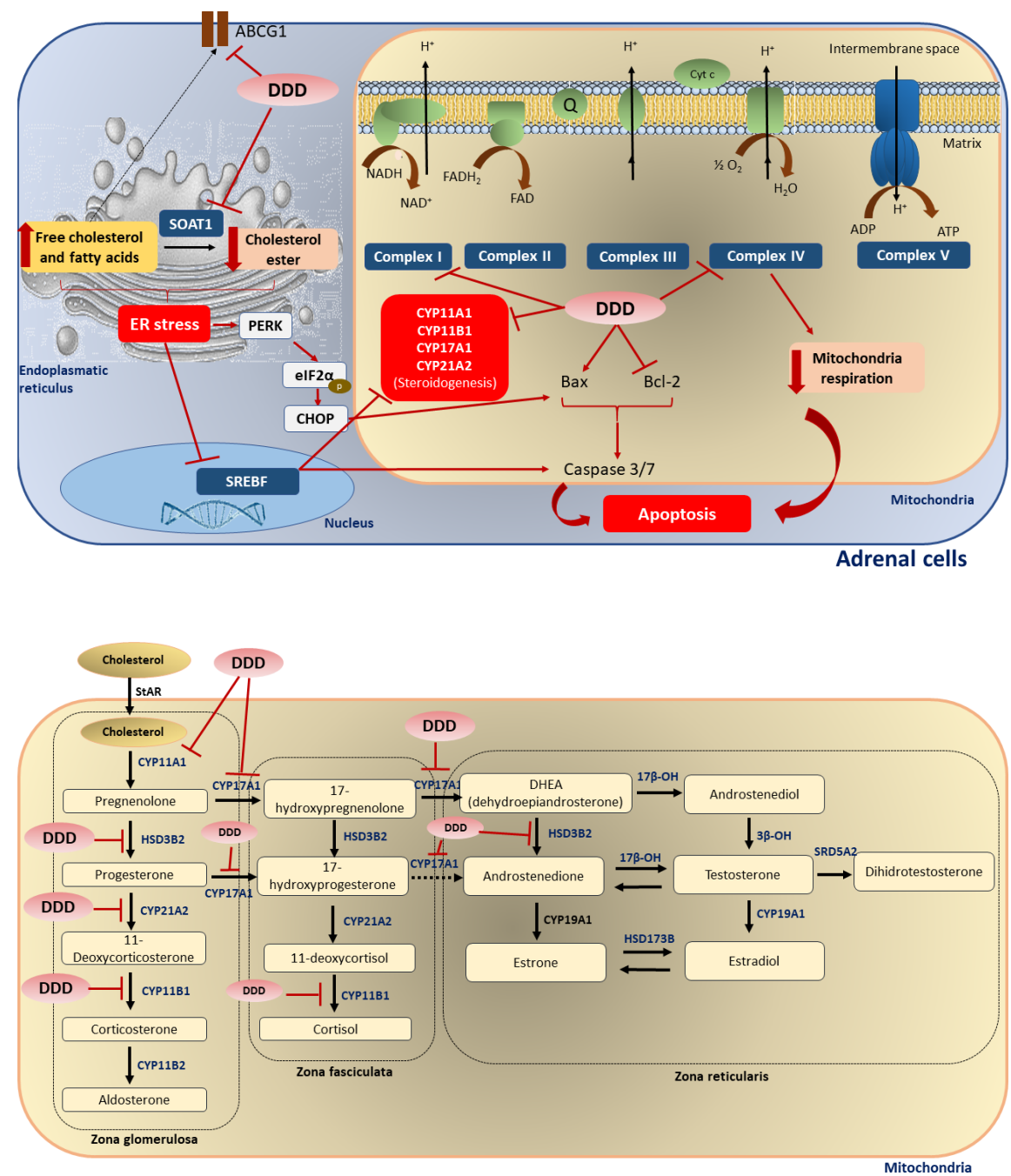